\title{
MYOCARDIAL PROTECTION IN NORMAL AND HYPOXICALLY STRESSED NEONATAL HEARTS: THE SUPERIORITY OF BLOOD VERSUS CRYSTALLOID CARDIOPLEGIA
}

Kirk Bolling, MD, $\mathrm{MPH}^{*}$

Michael Kronon, $\mathrm{MD}^{* *}$

Bradley S. Allen, MD

Tingrong Wang, MD

Shaik Ramon, MS

Harold Feinberg, $\mathrm{PhD}$
Objectives: Blood cardioplegia predominates in the adult because it provides superior myocardial protection, especially in the ischemically stressed heart. However, the superiority of blood over crystalloid cardioplegia in the pediatric population is unproved. Furthermore, because many pediatric hearts undergo a preoperative stress such as hypoxia, it is important to compare the different methods of protection in both normal and hypoxic hearts. Methods: Twenty neonatal piglets were supported by cardiopulmonary bypass and subjected to 70 minutes of cardioplegic arrest. Of 10 nonhypoxic hearts, five (group 1) were protected with blood cardioplegia and five (group 2) with crystalloid cardioplegia (St. Thomas' Hospital solution). Ten other piglets underwent 60 minutes of ventilator hypoxia (inspired oxygen concentration $8 \%$ to $10 \%$ ) before cardioplegic arrest. Five (group 3) were then protected with blood cardioplegia and the other five (group 4) with crystalloid cardioplegia. Myocardial function was assessed by means of pressure volume loops and expressed as a percentage of control. Coronary vascular resistance was measured with each infusion of cardioplegic solution. Results: No difference waas noted between blood (group 1) or crystalloid cardioplegia (group 2) in nonhypoxic hearts regarding systolic function (end-systolic elastance $104 \%$ vs $103 \%$ ), diastolic stiffness (156\% vs $159 \%$ ), preload recruitable stroke work (102\% vs $101 \%$ ), or myocardial tissue edema $(78.9 \%$ vs $78.9 \%)$. Conversely, in hearts subjected to a hypoxic stress, blood cardioplegia (group 3) provided better protection than crystalloid cardioplegia (group 4) by preserving systolic function (end-systolic elastance $106 \%$ vs $40 \% ; p<0.05$ ) and preload recruitable stroke work ( $103 \%$ vs $40 \%$; $p<0.05$ ); reducing diastolic stifiness $(153 \%$ vs $240 \% ; p<0.05)$ and myocardial tissue edema $(79.6 \%$ vs $80.1 \%)$; and preserving vascular function, as evidenced by unaltered coronary vascular resistance $(p<0.05)$. Conclusion: This study demonstrates that $(1)$ blood or crystalloid cardioplegia is cardioprotective in hearts not compromised by preoperative hypoxia and (2) blood cardioplegia is superior to crystalloid cardioplegia in hearts subjected to the preoperative stress of acute hypoxia. (J Thorac Cardiovasc Surg 1997;113:994-1005)
From the Division of Cardiothoracic Surgery, University of Illinois, Chicago, Ill.

Read at the Twenty-second Annual Meeting of The Western Thoracic Surgical Association, Maui, Hawaii, June 26-29, 1996.

Received for publication July 16, 1996; revisions requested August 27, 1996; revisions received Feb. 13, 1997; accepted for publication Feb. 13, 1997.

Address for reprints: Bradley S. Allen, MD, University of Illinois, Cardiothoracic Surgery Department, 840 S. Wood St., 417 CSB (M/C 958), Chicago, IL 60612.

${ }^{*}$ Samson Award Finalist.

* Supported in part by the Pillsbury Fellowship.

Copyright $(9) 1997$ by Mosby-Year Book, Inc.

$0022-5223 / 97 \$ 5.00+0 \quad \mathbf{1 2 / 6 / 8 1 1 2 5}$ ow cardiac output after surgically induced isch-emia continues to be a major contributor to morbidity and mortality in pediatric cardiac surgery. ${ }^{1-4}$ The neonatal heart has a reduced systolic and diastolic functional reserve, as well as a reduced response to inotropic agents, compared with the adult heart. $2,3,5,6$ Thus preservation of myocardial function in neonates during cardiac operations assumes even greater importance, because a perioperative insult is less well tolerated and more difficult to treat. Although numerous studies have compared blood cardioplegia with crystalloid cardioplegia in the mature heart, few have been done in the imma- 
ture heart. ${ }^{7-10}$ In addition, most studies have demonstrated conflicting results with no apparent difference between these two methods of myocardial protection in infants. ${ }^{2,-10}$ Therefore, although blood cardioplegia predominates in adult patients undergoing cardiac operations, crystalloid cardioplegia is still widely used in the pediatric population. $^{2}$ In view of the structural, functional, and metabolic differences, we believe that extrapolation of adult cardioplegia strategies to the neonate is imprudent. ${ }^{2,3,7}$ Instead, we think the question of blood versus crystalloid cardioplegia must be studied in the neonatal heart to resolve this continuing controversy.

Most studies examining the question of blood versus crystalloid cardioplegia in the newborn infant have used an isolated heart preparation that does not mimic the clinical setting., ${ }^{2,10}$ These results may therefore be misleading and not clinically applicable. In addition, these studies examined only normal (noninjured) neonatal hearts, whereas clinically many newborn hearts undergo a preoperative stress such as hypoxia, which alters the myocardium, rendering it more susceptible to a perioperative ischemic injury. ${ }^{11-15}$ In an attempt to address these concerns, this study compares blood versus crystalloid cardioplegia using a clinically relevant model (simulating the operating room) in both nonhypoxic (noninjured) and hypoxic ("stressed") neonatal hearts.

\section{Material and methods}

Twenty neonatal piglets ( 5 to 16 days old; 3.5 to $5 \mathrm{~kg}$ ) were premedicated with ketamine, $40 \mathrm{mg} / \mathrm{kg}$ given intramuscularly, and anesthetized with pentobarbital, $30 \mathrm{mg} / \mathrm{kg}$ given intraperitoneally and followed by $5 \mathrm{mg} / \mathrm{kg}$ given intravenously each hour. The lungs were ventilated via a tracheotomy with the use of a volume ventilator (Servo 900B, Siemens-Elema, Solna, Sweden). All animals received humane care in compliance with the "Principles of Laboratory Animal Care" formulated by the National Society for Medical Research, and the "Guide for the Care and Use of Laboratory Animals," prepared by the National Academy of Sciences and published by the National Institutes of Health (NIH publication No. 96-03, revised 1996).

The femoral artery and vein were cannulated to monitor arterial pressure, for blood gas determinations, and for intravenous infusions. After left thoracotomy, the coronary sinus was cannulated for blood sampling and pressure monitoring via the ligated hemiazygos vein. The heart was exposed by a median sternotomy, and transducer-tipped catheters (Millar Instruments, Inc., Houston, Tex.) were placed into the left ventricle, thoracic aorta (via the internal thoracic artery), left atrium, and pulmonary artery. The signals were routed to a recorder (model
Table I. Warm blood cardioplegic solution

\begin{tabular}{lrll}
\hline & $\begin{array}{c}\text { Volume } \\
\text { added } \\
\text { Cardioplegia additive }\end{array}$ & $\begin{array}{c}\text { Component } \\
\text { modified }\end{array}$ & $\begin{array}{c}\text { Concentration } \\
\text { delivered }\end{array}$ \\
\hline $\mathrm{KCl}(2 \mathrm{mEq} / \mathrm{ml})$ & 10 & $\mathrm{~K}^{+}$ & $8-10 \mathrm{mEq} / \mathrm{L}$ \\
THAM $(0.3 \mathrm{~mol} / \mathrm{L})$ & 225 & $\mathrm{pH}$ & $\mathrm{pH} 7.5-7.6$ \\
$\mathrm{CPD}$ & 225 & $\mathrm{Ca}^{++}$ & $0.2-0.3 \mathrm{mmol} / \mathrm{L}$ \\
Aspartate/glutamate & 250 & Substrate & $13 \mathrm{mmol} / \mathrm{L}$ each \\
$\mathrm{D}_{50} \mathrm{~W}$ & 40 & Glucose & $>400 \mathrm{mg} / \mathrm{dl}$ \\
$\mathrm{D}_{5} \mathrm{~W}$ & 200 & Osmolarity & $380-400 \mathrm{mOsm}$ \\
\hline
\end{tabular}

THAM, Tromethamine; $C P D$, citrate-phosphate-dextrose; $D_{50} W, 50 \%$ dextrose in water, $D_{5} W, 5 \%$ dextrose in water.

*When mixed in $4: 1$ ratio with blood.

4586C, Hewlett-Packard Company, Palo Alto, Calif.) by means of signal conditioners (model 8805C, HewlettPackard). A conductance catheter equipped with eight electrodes (Webster Laboratories, Baldwin Park, Calif.) was inserted through the left ventricular (LV) apex and the signals were routed to a Sigma-5 dual-field signal conditioner processor (Leycon, Cardiodynamics, Leiden, The Netherlands). After systemic heparinization (3 $\mathrm{mg} /$ $\mathrm{kg}$ ), a thin-walled venous cannula (18F) and an aortic cannula $(8 \mathrm{~F})$ were inserted into the right atrial appendage and left subclavian artery, respectively. An 18-gauge cardioplegia needle (DLP, Inc., Grand Rapids, Mich.) was inserted into the aorta for delivery of cardioplegic solutions. Arterial blood gases, electrolytes, and hemoglobin (Blood Gas System 288, Ciba Corning, Medfield, Mass.) were measured every 15 minutes to ensure optimal levels. A heating blanket was placed below the piglet, and a heating pad was placed on the abdomen to maintain a continuously monitored rectal temperature of $37^{\circ}$ to $38^{\circ} \mathrm{C}$. All external heat sources were discontinued during systemic cooling (see Cardioplegia protocols). The cardiopulmonary bypass (CPB) circuit was heparinized, primed with packed red cells from donor pigs, and in the blood cardioplegia group made normocalcemic with calcium chloride. The hematocrit value was adjusted to $25 \%$ to $35 \%$ with $0.9 \%$ normal saline solution (Baxter Healthcare Corp., Deerfield, Ill.). A Shiley Plexus membrane oxygenator (Shiley, Inc., Irvine, Calif.) was used and the aortic pressure kept between 30 and $50 \mathrm{~mm} \mathrm{Hg}$ by adjustment of the systemic flow to approximately $100 \mathrm{ml} / \mathrm{kg}$ per minute.

\section{Cardioplegia protocols}

Blood cardioplegia. Cardioplegic solutions (CAPS Service, Research Medical Inc., Salt Lake City, Utah) are shown in Tables I and II. Cardioplegia was produced by the use of a protocol of 5 minutes of warm $\left(37^{\circ} \mathrm{C}\right)$ induction followed by 5 minutes of cold $\left(4^{\circ} \mathrm{C}\right)$ induction, a 2-minute infusion of cold $\left(4^{\circ} \mathrm{C}\right)$ cardioplegic solution every 20 minutes, and a 4 -minute warm $\left(37^{\circ} \mathrm{C}\right)$ cardioplegic reperfusate ("hot shot") before aortic unclamping. Topical cooling with $4^{\circ} \mathrm{C}$ saline slush was applied during cold infusions and was removed before the warm reperfusate was administered. Cardioplegic solution was infused at a continuously measured aortic pressure of 40 to $50 \mathrm{~mm} \mathrm{Hg}$. Before the aorta was crossclamped, the piglets were cooled to $32^{\circ} \mathrm{C}$. After warm induction the temperature was further lowered to $25^{\circ} \mathrm{C}$, and rewarming to 
Table II. Cold blood cardioplegic solution

\begin{tabular}{lrll}
$\begin{array}{c}\text { Cardioplegia } \\
\text { additive }\end{array}$ & $\begin{array}{c}\text { Volume } \\
\text { added } \\
(\mathrm{ml})\end{array}$ & $\begin{array}{c}\text { Component } \\
\text { modified }\end{array}$ & $\begin{array}{c}\text { Concentration } \\
\text { delivered }^{*}\end{array}$ \\
\hline $\mathrm{KCl}(2 \mathrm{mEq} / \mathrm{ml})$ & 10 & $\mathrm{~K}^{+}$ & $8-10 \mathrm{mEq} / \mathrm{L}$ \\
$\mathrm{THAM}(0.3 \mathrm{~mol} / \mathrm{L})$ & 200 & $\mathrm{pH}$ & $\mathrm{pH} 7.6-7.8$ \\
$\mathrm{CPD}$ & 50 & $\mathrm{Ca}^{++}$ & $0.5-0.6 \mathrm{mmol} / \mathrm{L}$ \\
$\mathrm{D}_{5} \mathrm{~W} 1 / 4 \mathrm{NS}$ & 550 & Osmolarity & $340-360 \mathrm{mOsm}$ \\
\hline
\end{tabular}

THAM, Tromethamine; $C P D$, citrate-phosphate-dextrose; $D_{5} W, 5 \%$ dextrose in water; $N S$, normal saline solution.

*When mixed in 4:1 ratio with blood.

$37^{\circ} \mathrm{C}$ was begun 16 minutes before unclamping. $\mathrm{CPB}$ was discontinued 30 minutes after aortic unclamping, and final functional and biochemical measurements were made 30 minutes later, after arterial blood gases, calcium, and potassium were normalized.

Crystalloid cardioplegia. St. Thomas' Hospital solution (Plegisol, Abbott Laboratories, North Chicago, Ill.) was used for all infusions, and its composition is depicted in Table III. The cardioplegic solution was oxygenated and delivered at $4^{\circ} \mathrm{C}$ by means of this protocol: $20 \mathrm{mg} / \mathrm{kg}$ induction dose, $10 \mathrm{mg} / \mathrm{kg}$ every 30 minutes, and topical cooling with $4^{\circ} \mathrm{C}$ saline slush applied. Cardioplegic solution was infused at a continuously measured aortic pressure of 40 to $50 \mathrm{~mm} \mathrm{Hg}$. Reperfusion was begun by maintaining $\mathrm{CPB}$ at a mean pressure of $20 \mathrm{~mm} \mathrm{Hg}$ for 10 minutes and then increased slowly to 30 to $50 \mathrm{~mm} \mathrm{Hg}$. Before the aorta was crossclamped, piglets were cooled to a systemic temperature of $28^{\circ} \mathrm{C}$ with the use of a hypocalcemic prime. The temperature was further lowered to $25^{\circ} \mathrm{C}$ once cardioplegia was begun, and gradual rewarming to $37^{\circ} \mathrm{C}$ was begun 8 minutes before unclamping. $\mathrm{CPB}$ was discontinued 30 minutes after aortic unclamping, and final functional and biochemical measurements were made 30 minutes later, after arterial blood gases, calcium, and potassium were normalized.

Physiologic measurements. Coronary vascular resistance (CVR) was determined during each infusion of cardioplegic solution by measuring coronary sinus pressure and cardioplegia flow once a constant infusion rate with an aortic pressure between 40 to $50 \mathrm{~mm} \mathrm{Hg}$ was achieved. CVR was calculated by the formula:

$\operatorname{CVR}\left(\right.$ dynes $\left.\cdot \mathrm{sec}^{-1} \cdot \mathrm{cm}^{-5}\right)=$

$$
\frac{\text { CIP }- \text { CSP }}{\text { Cardioplegia flow }} \times 80
$$

where CIP $=$ cardioplegia infusion pressure and CSP $=$ coronary sinus pressure.

Myocardial performance. LV pressure and conductance catheter signals were amplified and digitized to inscribe LV pressure volume loops after first correcting for parallel conductance (myocardial tissue and blood viscosity) with the use of hypertonic saline solution according to the method of Baan, Van Der Velde, and Steendijk. ${ }^{16}$ A series of pressure volume loops was generated under varying conditions by transient occlusion of the inferior vena cava during an 8-second period of apnea.
Table III. Composition of St. Thomas' Hospital (Plegisol) cardioplegic solution*

\begin{tabular}{ll} 
Osmolarity (mOsm) & 324 \\
$\mathrm{pH}$ & $\mathrm{pH} 7.8$ \\
Potassium & $16 \mathrm{mEq} / \mathrm{L}$ \\
Calcium & $1.2 \mathrm{mmol} / \mathrm{L}$ \\
Magnesium & $32 \mathrm{mEq} / \mathrm{L}$ \\
Sodium & $120 \mathrm{mEq} / \mathrm{L}$ \\
Chloride & $160 \mathrm{mEq} / \mathrm{L}$ \\
\hline
\end{tabular}

*When mixed with $10 \mathrm{ml}(10 \mathrm{mEq})$ of $8.4 \%$ sodium bicarbonate.

Measurements were made before hypoxia or $\mathrm{CPB}$ (control) and 30 minutes after CPB was discontinued. The end-systolic and end-diastolic pressure volume relationship and the preload recruitable stroke work relationship were analyzed with the use of a computer graphics program (Spectrum, Bowman-Gray School of Medicine, Winston-Salem, N.C.) on a 486-33 $\mathrm{MHz}$ Dell personal computer (Dell Computer Corp., Austin, Tex.). LV systolic performance was determined from the descending slope of the end-systolic pressure volume relationship by means of linear regression analysis and designated as end-systolic elastance. End-diastolic compliance was determined from the exponential regression of the end-diastolic pressure volume relationship. Global myocardial performance was assessed by preload recruitable stroke work, which was calculated as the integral of LV transmural pressure and cavity volume over each cardiac cycle. Functional measurements are expressed as percent recovery of baseline values with each piglet acting as its own control. After final hemodynamic measurements, all piglets were again supported with $\mathrm{CPB}$ and cooled. Hearts were then arrested with cold $\left(4^{\circ} \mathrm{C}\right)$ cardioplegic solution and transmural LV biopsies obtained. Endocardial and epicardial portions were separated, frozen quickly in liquid nitrogen, and stored for biochemical analysis. A separate sample was obtained for myocardial water.

Biochemical analysis. Samples were crushed in a liquid nitrogen-cooled mortar and pestle and lyophilized (Savant Speed Vac Systems, Farmingdale, N.Y.). The adenosine pool was determined according to the method of Sarin and colleagues. ${ }^{17}$ Ten to fifteen milligrams of dry tissue was extracted with $0.6 \mathrm{~mol} / \mathrm{L}$ perchloric acid, the protein-free supernatant was neutralized by a mixture of $\mathrm{KHCO}_{3}$ in $0.5 \mathrm{~mol} / \mathrm{L}$ tromethamine (Tris) buffer ( $\mathrm{pH} 7.5$ ), and the neutralized solution was allowed to stand at $4^{\circ} \mathrm{C}$ to precipitate $\mathrm{KCLO}_{4}$. Aliquots of the neutralized extract were analyzed with a high performance liquid chromatograph (Waters Inc., Milford, Mass.) equipped with a Waters Nova-Pak column. The adenosine pool was isocratically eluted with a mobile phase consisting of 0.1 $\mathrm{mol} / \mathrm{L}$ ammonium phosphate $(5.0 \mathrm{nmol} / \mathrm{L})$ (tetrabutylammonium hydroxide $\mathrm{pH} 5.0$ ) and detected at $233 \mathrm{~nm}$. Adenosine triphosphate (ATP) levels are expressed as micrograms per gram dry tissue.

Myocardial water. Ventricular samples were placed in a preweighed vial and dried to a constant weight at a temperature of $85^{\circ} \mathrm{C}$. Myocardial water was calculated by means of the following formula: 

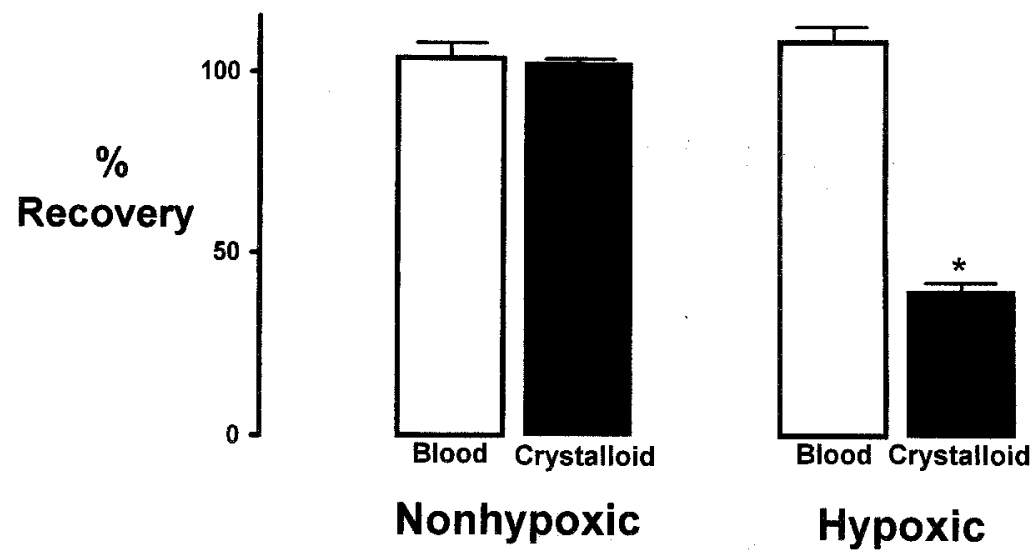

Fig. 1. LV systolic function as measured by end-systolic elastance and expressed as a percentage of control. Note: There is complete preservation of systolic function independent of the type of cardioplegic solution used in noninjured (nonhypoxic) hearts. In hypoxic hearts, blood cardioplegic solution allowed for cellular repair of the hypoxic reoxygenation injury with complete return of systolic function. In contrast, systolic function is diminished in hypoxic hearts protected with a crystalloid cardioplegic solution. (See text for details.) $* p<0.0001$.

Percent myocardial water $=$

$$
\frac{\text { Wet weight }- \text { Dry weight }}{\text { Wet weight }} \times 100
$$

Experimental groups

Nonhypoxemic (uninjured hearts) studies. After CPB was begun, 10 piglets underwent 70 minutes of cardioplegic arrest with either the blood (group 1, $n=5$ ) or crystalloid (group $2, n=5$ ) cardioplegia protocol outlined herein.

Hypoxemic (stress) studies. Ten other piglets underwent 60 minutes of ventilator hypoxia by lowering the fraction of inspired oxygen to $8 \%$ to $10 \%$, producing an arterial oxygen tension of 25 to $35 \mathrm{~mm} \mathrm{Hg}$ and an oxygen saturation of $65 \%$ to $70 \%$. Before hypoxemia, piglets were given transfusions as necessary to increase the hematocrit value to greater than $35 \%$. This condition simulates the chronic adaptive change of erythrocytosis that occurs in the cyanotic infant and increases oxygen-carrying capacity, thereby allowing ischemia to be avoided during hypoxia. All piglets remained in hemodynamically stable condition during the entire 60 minutes of ventilator hypoxia. At the end of 60 minutes, all piglets were placed on $\mathrm{CPB}$ at an inspired oxygen concentration of $100 \%$ to produce a reoxygenation injury. ${ }^{18,19}$ The aorta was clamped and piglets underwent 70 minutes of cardioplegic arrest with either the blood (group 3, $n=5$ ) or crystalloid (group 4, $n=5$ ) cardioplegia protocol outlined earlier.

Statistics. Data were analyzed by means of JMP V2.0 (SAS Institute, Inc., Cary, N.C.) on a Macintosh IIVX computer (Apple Inc., Cupertino, Calif.). Paired Student's $t$ test and two-way analysis of variance with interaction (factorial analysis) were used for comparison of variables among experimental groups. If the analysis of variance revealed a significant interaction, pairwise tests of individual group means were compared by means of multiple comparisons (Tukey's test). Group data are expressed as mean \pm standard error of the mean. Values of $p<0.05$ were considered to be statistically significant:

\section{Results}

No difference between groups was noted for control values of $L V$ contractility, diastolic compliance, or global myocardial function. Hypoxia resulted in an increase in heart rate from 130 to 150 beats/min up to 190 to 220 beats/min, decreased systemic vascular resistance index, increased pulmonary vascular resistance index, and did not significantly affect cardiac output. All piglets tolerated 60 minutes of hypoxia with stable hemodynamics.

Hemodynamics and physiologic measurements. Results are seen in Figs. 1 through 5. There was no change or difference in the $\mathrm{X}$ intercept $\left(\mathrm{V}_{0}\right)$ for end-systolic elastance or preload recruitable stroke work between prebypass (control) and postbypass values in any experimental group. Therefore the change in slope of end-systolic elastance, preload recruitable stroke work, and diastolic compliance can be interpreted to express variability in the contractile state of the myocardium compared with control values. In nonhypoxic hearts, no difference $(p>0.05)$ was found between blood (group 1) or crystalloid cardioplegia (group 2) regarding postbypass systolic function (end-systolic elastance 104\% $\pm 4 \%$ vs $103 \% \pm 1 \%)$, diastolic stiffness $(156 \% \pm$ $5 \%$ vs $159 \% \pm 3 \%$ ), or preload recruitable stroke 


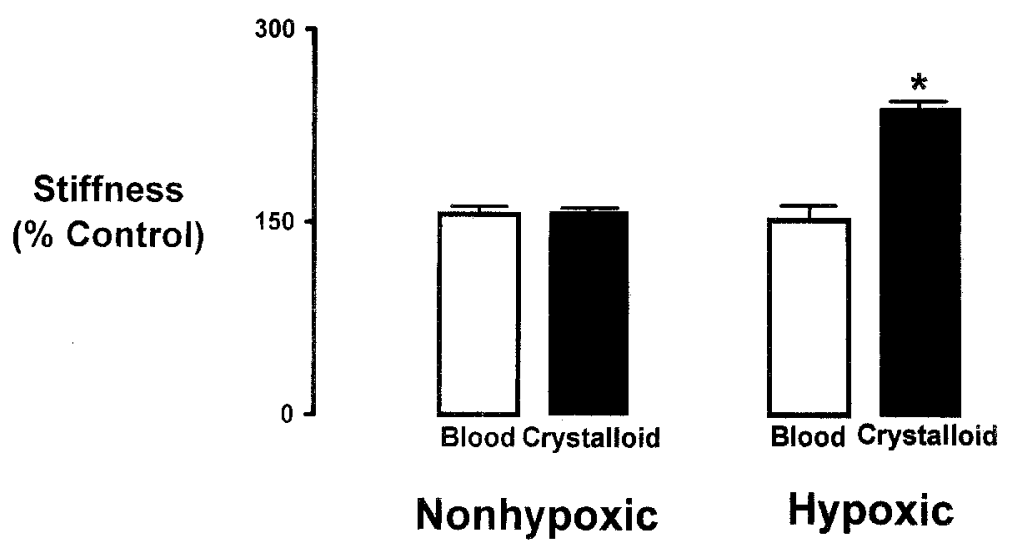

Fig. 2. LV diastolic compliance as measured by end-diastolic pressure volume relationship and expressed as a percentage of stiffness compared with control. Note: There is only minimal increase in diastolic stiffness in noninjured (nonhypoxic) hearts independent of the type of cardioplegic solution used. In hypoxic hearts, blood cardioplegic solution allowed for cellular repair of the hypoxic reoxygenation injury, resulting in only mild increase in diastolic stiffness, which is not statistically different from noninjured hearts. Conversely, there was a marked increase in diastolic stiffness in hypoxic hearts protected with a crystalloid cardioplegic solution. (See text for details.) $* p<0.0001$.

work $(102 \% \pm 2 \%$ vs $101 \% \pm 1 \%)$ (Figs. 1 to 3 ). Conversely, in hearts subjected to prebypass hypoxia, blood cardioplegia (group 3) provided superior protection by preserving systolic function (end-systolic elastance $106 \% \pm 3 \%$ vs $40 \% \pm 1 \% ; p<$ $0.0001)$ and preload recruitable stroke work $(103 \%$ $\pm 1 \%$ vs $40 \% \pm 1 \% ; p<0.0001)$ and reducing diastolic stiffness $(153 \% \pm 12 \%$ vs $240 \% \pm 4 \%: p<$ 0.0001) compared with crystalloid cardioplegia (group 4) (Figs. 1 to 3). There was no change in CVR during cardioplegic infusions in hearts receiving blood cardioplegia with or without preceding hypoxia (Fig. 4). In contrast, although lower in both crystalloid groups, CVR rose markedly in hypoxic hearts receiving crystalloid cardioplegia (group 4), indicating vascular dysfunction (Fig. 5).

Tissue studies. Results are summarized in Table IV. Although no statistically significant difference in ATP was noted among the four groups, ATP levels were lowest in hypoxic hearts protected with a crystalloid cardioplegic solution (group 4). However, a significant interaction between stress (hypoxia) and type of cardioplegic solution was noted for the ratio of adenosine tripnosphate to diphosphate (ATP/ADP) $(F=6.5, p=0.02)$. This ratio, which reflects the ability of the mitochondria to phosphorylate ADP to ATP, was markedly reduced in both groups of hearts protected with a crystalloid cardioplegic solution (groups 2 and 4), suggesting mitochondrial damage, especially in hypoxic hearts (group 4). There was also a significant interaction for myocardial water $(F=5.1, p=0.04)$. Although the highest amount of cellular water $(80.1 \% \pm .1 \%)$ was found in hypoxic hearts protected with crystalloid cardioplegia (group 4), indicating the greatest degree of cellular injury, there was no statistically significant difference between this group and hypoxic hearts subjected to blood cardioplegia $(80.1 \%$ vs $79.6 \%$ )

\section{Discussion}

This study demonstrates that in the clinically relevant intact animal model simulating operating room conditions, (1) blood and crystalloid cardioplegia both provide good myocardial protection of neonatal hearts not subjected to a preoperative stress, (2) hypoxic (stressed) neonatal hearts are more dependent on the type of cardioplegic protection, and (3) the optimal method of myocardial protection of hypoxically "stressed" hearts is achieved with blood cardioplegia.

In contrast to studies in the adult, most studies conducted in newborn infants have shown little difference between blood and crystalloid cardioplegia. ${ }^{2,8-10}$ This inability to demonstrate a difference may be due to various factors. Unlike adult studies, most neonatal investigations have used an isolated heart model. ${ }^{2,8-10}$ Although this allows for precise experimental control, it does not mimic clinical conditions of the operating room. For instance, 
The Journal of Thoracic and

Cardiovascular Surgery

Volume 113, Number 6

Bolling et al. 999

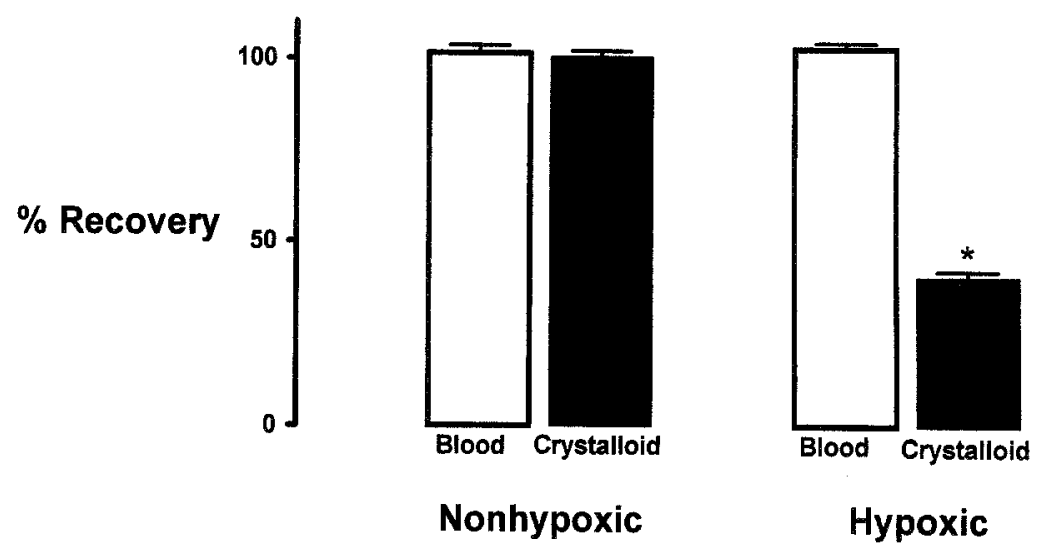

Fig. 3. Overall LV myocardial function as measured by preload recruitable stroke work and expressed as a percentage of control. Note: There is complete preservation of global myocardial function independent of the type of cardioplegic solution in noninjured (nonhypoxic) hearts. In hypoxic hearts, blood cardioplegic solution allowed for cellular repair of the hypoxic reoxygenation injury with complete preservation of global myocardial function. In contrast, there is depressed global myocardial function in hypoxic hearts protected with a crystalloid cardioplegic solution, indicating cellular damage. (See text for details.) ${ }^{*} p<0.0001$.

bronchial blood return and noncoronary collateral flow are absent in the isolated heart but may have a profound effect in the in vivo model, because the cardioplegic solution may be washed away, changing the cellular environment. ${ }^{7}$ Hypothermia, which may provide the dominate protective effect, is easier to maintain in the isolated heart preparation, whereas the heart is constantly rewarmed in the intact animal setting. ${ }^{2,3,8}$ Furthermore, despite the prevalence of preoperative stresses such as hypoxia in the neonatal population, few studies have included such hearts in their investigations. However, hypoxia has been shown to significantly alter the myocardium and affect cardioplegic protection. Therefore we examined blood and crystalloid cardioplegia in neonatal hearts using (1) a model that mimics operating room conditions and (2) noninjured (nonhypoxic) and hypoxic (stressed) neonatal hearts.

In nonhypoxic (noninjured) hearts, myocardial function was completely preserved with either cardioplegic solution (see Figs. 1 to 3). Myocardial edema and ATP levels were also unchanged, indicating that the two cardioplegic solutions provide similar protection. However, in this study the ischemic (crossclamp) time was relatively short, and the neonatal myocardium is more tolerant of ischemia than the adult. ${ }^{2,3}$ Inasmuch as a reperfusion injury is dependent on the duration of ischemia, these factors may have accounted for the lack of difference seen between these two groups. ${ }^{7}$ It is possible that differ- ences may have been seen had the crossclamp time been extended, especially since the ATP/ADP ratio was significantly reduced in both crystalloid groups (see Table IV). Furthermore, in clinical practice congenital lesions usually result in hypoxia or pressure-volume overload; therefore "normal" hearts are probably uncommon, especially in the neonatal population.

An increasing number of infants with cyanotic congenital heart disease are undergoing primary repair., ${ }^{2,3}$ Although repair may be preferable to palliation, it subjects the immature hypoxic heart to high oxygen levels during $\mathrm{CPB}$, a condition that has been shown to cause an unintended reoxygenation injury ${ }^{18,19}$ This injury, which is mediated by oxygenderived free radicals, results in myocardial depression and may explain the reason for myocardial necrosis and impairment of ventricular function after apparently successful surgical correction of cyanotic congenital defects. ${ }^{6,14,18-20}$ Despite the prevalence of hypoxia in the neonatal population, no studies have examined the question of blood versus crystalloid cardioplegia in a clinically relevant (stressed) hypoxic model. Including stressed hearts in any investigation of cardioplegic solutions is important because the results can be dramatically altered. ${ }^{9,11,13}$ This is the reason that adult studies of various cardioplegic solutions imposed a preischemic stress. ${ }^{7}$ However, because pediatric hearts do not usually experience severe preoperative ischemia, 


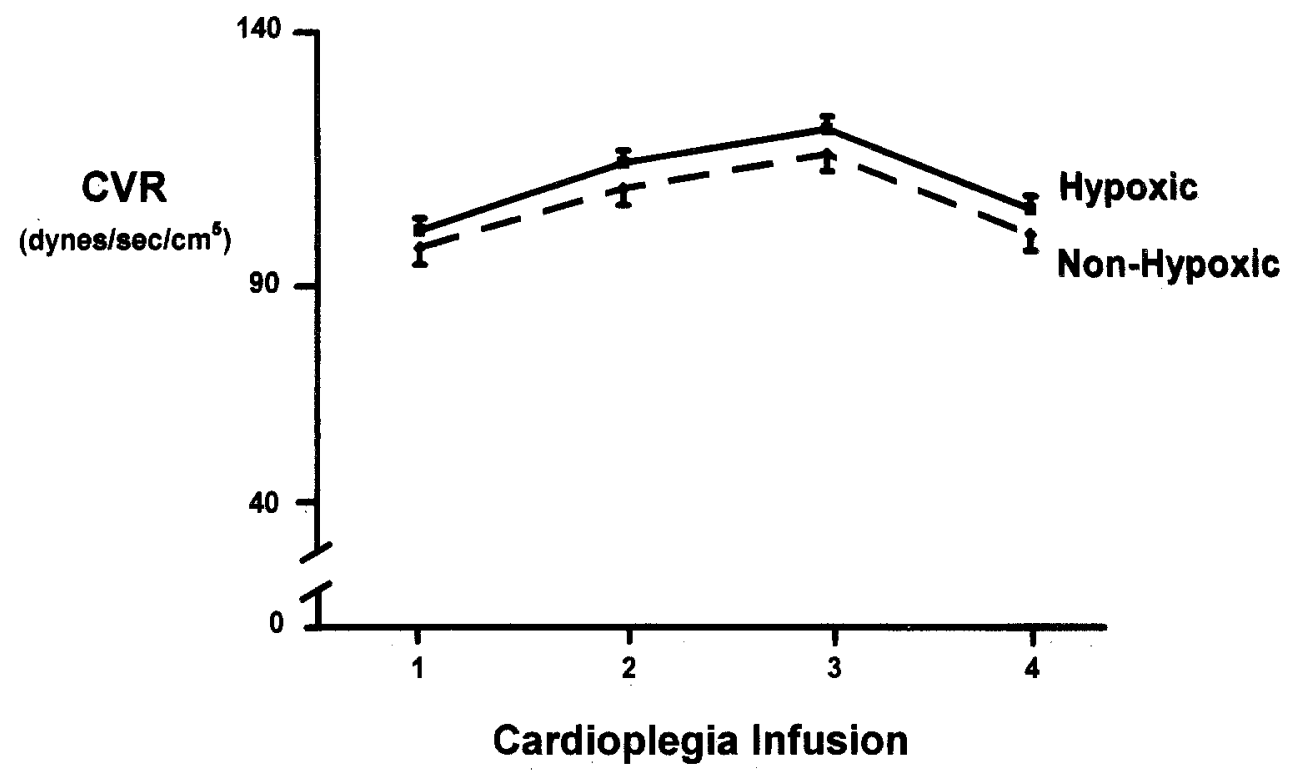

Fig. 4. CVR in hypoxic and nonhypoxic hearts measured during each blood cardioplegic infusion. Cardioplegic infusions 1 and 4 were during warm $\left(37^{\circ} \mathrm{C}\right)$ induction and reperfusion, respectively, and 2 and 3 were during cold $\left(4^{\circ} \mathrm{C}\right)$ multidose infusions. Note: There is no difference $(p>0.05)$ in CVR in hearts protected with a blood cardioplegic solution, indicating that blood cardioplegia preserves vascular function despite a hypoxic stress. (See text for details.)

the injury must be changed to reflect a clinically relevant stress, such as hypoxia.

Subjecting the neonatal piglet to acute hypoxia profoundly altered the effect of the cardioplegic solutions on the myocardium. Blood cardioplegic solutions not only protected the heart from further damage but also facilitated repair of the injury caused by hypoxia and reoxygenation, resulting in complete preservation of myocardial and vascular function (see Figs. 1 to 4). Conversely, a cellular injury occurred in hypoxic hearts protected with crystalloid cardioplegic solutions. This injury was manifest by depression in postbypass myocardial and vascular function (see Figs. 1 to 3 and Fig. 5). Although our model of acute hypoxia does not allow for the chronic adaptive changes that may occur in cyanotic newborn infants, it does subject the heart to a clinically relevant "stress." Several studies have documented a similar oxygen-mediated injury with reoxygenation of the chronically hypoxic infant, and we recently documented an identical injury in 21 cyanotic infants using the same biochemical test as our acute experimental studies. ${ }^{21-23}$ In addition, our results demonstrating an increased sensitivity to crystalloid cardioplegia after acute hypoxia are similar to those obtained in piglets subjected to chronic hypoxia $^{11,12}$ and to those obtained in cyanotic in- fants, ${ }^{1,2,14}$ leading us to believe our experimental findings are clinically relevant.

Vascular function was determined by measuring CVR during each infusion of cardioplegic solution when the heart was arrested and the flow rate and infusion pressure were constant. Although the CVR may change between warm and cold cardioplegia and between blood and crystalloid cardioplegia, it should be identical for each solution at a given temperature because our experimental model of hypoxia does not result in ischemia. This is exactly what was seen in piglets protected with blood cardioplegia: no difference in CVR was detected between hypoxic and nonhypoxic hearts, indicating preservation of vascular function despite an acute hypoxia stress injury (see Fig. 4). In contrast, although the CVR was lower in the crystalloid groups because of the lower viscosity, there was a marked increase in CVR in hypoxic hearts during each infusion of cardioplegic solution (group 4), implying that vascular function was compromised (see Fig. 5). The only other reason for this increased CVR would be vascular compression from increased myocardial water. However, no significant difference in myocardial edema was noted between blood-perfused and crystalloid-perfused hearts subjected to hypoxia. Therefore, CVR was increased only in hypoxic 


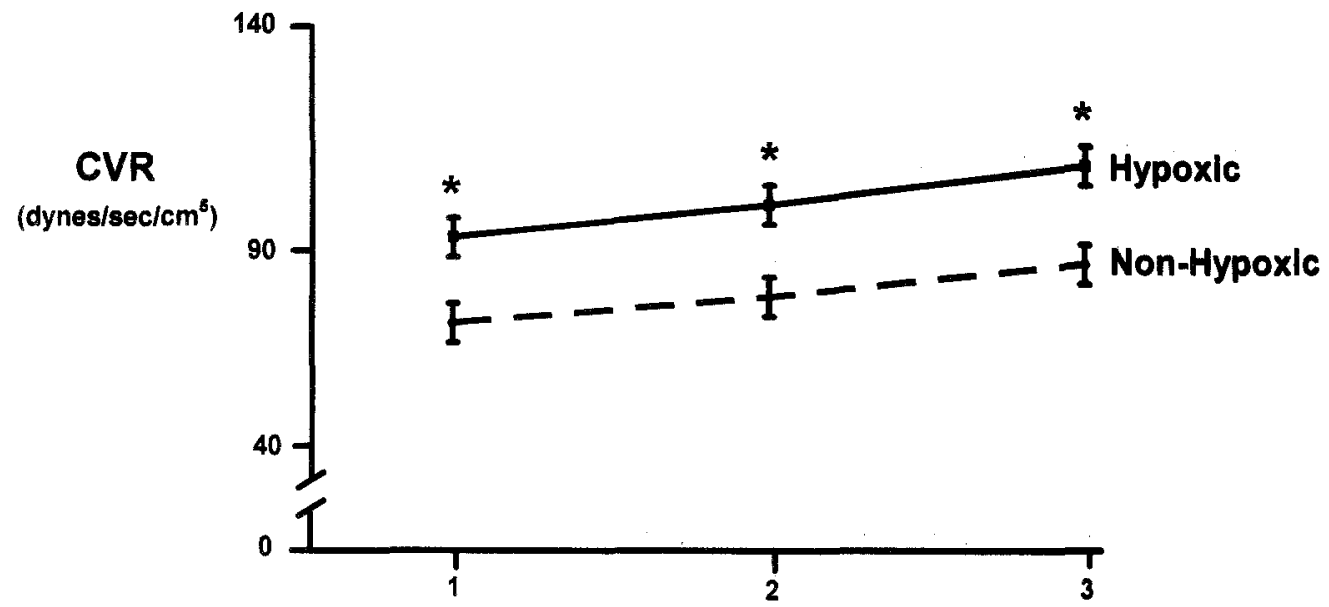

Cardioplegia Infusion

Fig. 5. CVR in hypoxic and nonhypoxic hearts measured during each crystalloid cardioplegic infusion. All cardioplegic infusions were delivered cold $\left(4^{\circ} \mathrm{C}\right)$. Note: There is a marked rise in CVR when a crystalloid cardioplegic solution is used in hypoxic hearts, indicating a derangement in vascular function. (See text for details.) $* p=0.001$.

hearts subjected to crystalloid cardioplegia, a fact that supports a derangement in vascular function, not edema. Furthermore, this increased CVR may have resulted in less homogeneous distribution of the cardioplegic solution during ischemia, thereby compromising myocardial protection during cardiac arrest. We did not measure vascular function after discontinuing $\mathrm{CPB}$. However, because myocardial function was still depressed after CPB in hypoxic hearts protected with a crystalloid cardioplegic solution, it is likely that vascular function was similarly affected.

Blood cardioplegia has several advantages over crystalloid cardioplegia which help to explain our findings. ${ }^{7}$ The heart is arrested in an oxygenated environment so that no loss of high-energy phosphate stores occurs during the short period of electromechanical activity before asystole. ${ }^{7}$ Several investigators have reported significant decreases in high-energy phosphates during the few heartbeats occurring during induction with crystalloid cardioplegia. Because the hypoxic heart has been shown both clinically and experimentally to have an increased susceptibility to ATP depletion during surgically induced ischemia, this may be partially responsible for the improvement seen in the blood cardioplegia groups. ${ }^{12,14}$ When given as a warm induction, blood cardioplegic solutions can "resuscitate" the injured myocardium, thereby allowing it to better tolerate the imposed period of surgical
Table IV. Endocardial tissue results

\begin{tabular}{|c|c|c|c|}
\hline Group & $\begin{array}{l}\text { ATP } \\
(\mu g / g m \\
\text { tissue) }\end{array}$ & $\begin{array}{c}A T P / A D P \\
\text { ratio }\end{array}$ & Water (\%) \\
\hline $\begin{array}{l}\text { Normal (nonhypoxic) } \\
\text { heart/blood (group 1) }\end{array}$ & $15.8 \pm 0.4$ & $4.3 \pm 0.3$ & $78.9 \pm 0.4$ \\
\hline $\begin{array}{l}\text { Normal (nonhypoxic) } \\
\text { heart/crystalloid } \\
\text { (group 2) }\end{array}$ & $15.6 \pm 0.7$ & $3.3 \pm 0.4^{*}$ & $78.9 \pm 0.2$ \\
\hline $\begin{array}{l}\text { Hypoxic heart/blood } \\
\text { (group 3) }\end{array}$ & $15.3 \pm 1.1$ & $4.1 \pm 0.2$ & $79.6 \pm 0.6$ \\
\hline $\begin{array}{l}\text { Hypoxic heart/ } \\
\text { crystalloid } \\
\text { (group 4) }\end{array}$ & $13.3 \pm 0.8$ & $2.6 \pm 0.4 \uparrow$ & $80.1 \pm 0.1+$ \\
\hline
\end{tabular}

ischemia. ${ }^{72}$ Blood cardioplegic solutions also provide oxygen and nutrients during multidose infusions to enhance cellular metabolism and replenish depleted energy storage. ${ }^{7}$ Last, because the hypoxic heart may be more susceptible to a reperfusion injury after ischemia, use of a warm reperfusate (hot shot) can modify this injury before the aortic crossclamp is removed. ${ }^{7,25}$

Tissue ATP levels seem to support this hypothesis. In both blood cardioplegia groups, ATP levels and the ATP/ADP ratio remained unaffected despite the stress of preoperative hypoxia (see Table 
IV). Conversely, although crystalloid cardioplegia was able to maintain ATP levels in normal hearts, the high-energy phosphates were reduced in those hearts subjected to preoperative hypoxia. In addition, the ATP/ADP ratio fell in all piglets protected with crystalloid cardioplegia, especially those subjected to hypoxia (group 4). This seems to indicate that mitochondrial damage resulting in a decreased ability to convert ADP to ATP is indeed present. These findings parallel those seen clinically in patients with tetralogy of Fallot, in whom ATP levels are significantly depressed and decreased ventricular function is often present after surgical correction. ${ }^{6,12,14,20}$ In addition, because low postischemic ATP levels in infants correlate with poor postoperative ventricular function, these findings, along with the functional data, suggest that crystalloid cardioplegia provides inadequate protection in hypoxic hearts. ${ }^{11,15}$ Unlike ischemic models, our experimental model of acute hypoxia does not cause significant depletion of nucleotide stores (unpublished data). However, chronically cyanotic hearts may be predisposed to accelerated depletion of these high-energy compounds during periods of increased myocardial oxygen demands associated with exercise or surgically induced ischemia during operative repair. ${ }^{26,27}$ Therefore the effects of crystalloid cardioplegic solutions may even be more pronounced in the clinical setting and may explain why myocardial necrosis is common after repair of cyanotic congenital heart defects. ${ }^{14}$

We did not test every crystalloid cardioplegic solution or strategy currently available. The optimum crystalloid cardioplegic solution was not the aim of the current study. The crystalloid cardioplegic solution and strategy used was chosen because it has been extensively investigated and is advocated by surgeons at the Boston Children's Hospital. ${ }^{2,9,11,28}$ Unlike other investigators, we chose to deliver each cardioplegic solution as it is delivered clinically, using those strategies that have been shown to optimize protection. 2, 7, 11, 28, 29 Therefore the protocols for blood and crystalloid cardioplegia differed slightly. Although using identical cardioplegic protocols may be preferred scientifically, it does not allow one to test each solution to its maximal clinical potential. For instance, both warm induction and reperfusion were used for blood cardioplegia because these methods have been shown to improve protection in stressed adult hearts. ${ }^{7}$ In contrast, no warm crystalloid infusions were given, because no such benefits have been demonstrated. To maximize crystalloid protection, hearts were cooled with the use of a hypocalcemic bypass prime; the cardioplegic solution was oxygenated and delivered at a low pressure; the heart was kept cool with topical $\left(4^{\circ} \mathrm{C}\right)$ cooling; and reperfusion was begun at $20 \mathrm{~mm}$ $\mathrm{Hg}$ and increased slowly. It is possible that had other crystalloid solutions or strategies been used, different results may have been obtained. However, because we incorporated all of the strategies that have been shown to optimize crystalloid cardioplegia protection and administered the solution as recommended by numerous clinical and experimental investigators, we believe our method represents a fair comparison. $, 7,7,11,28,29$

In summary, this study demonstrates that in a clinically relevant model both blood and crystalloid cardioplegia provide excellent myocardial protection in nonhypoxic (noninjured) hearts subjected to a short ischemic interval. Conversely, when the heart is subjected to a preoperative hypoxic stress, the type of cardioplegia takes on an increased importance, with blood cardioplegia providing superior myocardial protection. Because cyanotic hearts are often depressed after apparently successful surgical repair, this study suggests that a blood cardioplegic solution should be used to ensure optimal protection.

We gratefully acknowledge Ms. Peggy Burse and Ms. Kym Montecinos, for their organizational and secretarial assistance, and Dibyen Majumdar, $\mathrm{PhD}$, for statistical consultation.

\section{REFERENCES}

1. Bull C, Cooper J, Stark J. Cardioplegic protection of the child's heart. J Thorac Cardiovasc Surg 1984;88:287.

2. Castaneda AR, Jonas RA, Mayer JE Jr, Hanley FL. Myocardial preservation in the immature heart. In: Castaneda AR, Jonas RA, Mayer JE Jr, Hanley FL, editors. Cardiac surgery of the neonate and infant. Philadelphia: WB Saunders; 1994. p. 41-54.

3. Hammon JW Jr. Myocardial protection in the immature heart. Ann Thorac Surg 1995:60:839-42.

4. Kirklin J, Blackstone E, McKay R, Pacifico A, Bargeron L. Intracardiac surgery in infants under age 3 months: incremental risk factors for hospital mortality. Am J Cardio 1981;48:500-6.

5. Romero TE, Friedman WF. Limited left ventricular response to volume overload in the neonatal period: a comparative study with the adult animal. Pediatr Res 1979;13:910-5.

6. Jarmakani JM, Graham TP, Canent RV, Jewett PH. Left heart function in children with tetralogy of Fallot before and after palliative or corrective surgery. Circulation 1972;46:47890.

7. Buckberg GD, Allen BS. Myocardial protection management during adult cardiac operations. In: Baue AE, Geha AS, Hammond GL, Laks H, Naunheim KS, editors. Glenn's thoracic and cardiovascular surgery. 6 th ed. Stamford [CT]: Appleton \& Lange; 1995. p. 1653-87. 
8. Corno AF, Bethencourt DM, Laks $\mathrm{H}$, Haas GS, Bhuta $\mathrm{S}$, Davtyan HG, et al. Myocardial protection in the neonatal heart: a comparison of topical hypothermia and crystalloid and blood cardioplegic solutions. J Thorac Cardiovasc Surg 1987;93:163-72.

9. Fujiwara T, Heinle J, Britton L, Mayer JE Jr. Myocardial preservation in neonatal lambs: comparison of hypothermia with crystalloid and blood cardioplegia. J Thorac Cardiovasc Surg 1991;101:703-12.

10. Pearl JM, Laks H, Drinkwater DC, Meneshian A, Sun B, Gates RN, et al. Normocalcemic blood or crystalloid cardioplegia provides better neonatal myocardial protection than does low-calcium cardioplegia. J Thorac Cardiovasc Surg 1993;105:201-6.

11. Fujiwara T, Kurtts T, Anderson W, Heinle J, Mayer JE Jr. Myocardial protection in cyanotic neonatal limbs. J Thorac Cardiovase Surg 1988;96:700-10.

12. Silverman N, Kohler J, Levitsky S, Pavel D, Fang R, Feinberg H. Chronic hypoxemia depresses global ventricular function and predisposes to depletion of high energy phosphates during cardioplegic arrest: implications for surgical repair of cyanotic congenital heart defects. Ann Thorac Surg 1984:37: 304-8.

13. Lupinetti FM, Wareing TH, Huddleston $\mathrm{CB}$, Collins JC, Boucek RJ Jr, Bender HW Jr, et al. Pathophysiology of chronic cyanosis in a canine model. J Thorac Cardiovasc Surg 1985;90:291-6.

14. Deil Nido PJ, Mickle DAG, Wilson GJ, Benson LN, Weisel $\mathrm{RD}$, Coles $\mathrm{JG}$, et al. Inadequate myocardial protection with cold cardioplegic arrest during repair of tetralogy of Fallot. J Thorac Cardiovasc Surg 1988;95:223-9.

15. Hammon JW Jr, Graham TP Jr, Boucek RJ Jr, Parrish MD, Merrill WH, Bender HW Jr. Myocardial adenosine triphosphate content as a measure of metabolic and functional myocardial protection in children undergoing cardiac operation. Ann Thorac Surg 1987;44:467-70.

16. Baan J, Van Der Velde E, Steendijk P. Ventricular pressure volume relations in vivo. Eur Heart J 1992;13;Suppl E:2-6.

17. Sarin M, Buinevicius Z, Levitsky S, Feinberg H. Isocratic high-performance liquid chromatographic analysis of myocardial creatine phosphate and adenine nucleotides. J Chromatogr 1991;563:129-33.

18. Ihnken K, Morita K, Buckberg GD. Matheis G, Sherman MP, Allen BS, et al. Studies of hypoxemic/reoxygenation injury: without aortic clamping. II. Evidence for reoxygenation damage. J Thorac Cardiovase Surg 1995;110:1171-81.

19. Buckberg GD. Studies of hypoxemic/reoxygenation injury. I. Linkage between cardiac function and oxidant damage. J Thorac Cardiovase 1995;110:1164-70.

20. Rocchini AP, Keane JF, Castaneda AR, Nadas AS. Left ventricular function following attempted surgical repair of tetralogy of Fallot. Circulation 1978:57:798-802.

21. Teoh KH, Mickle DAG, Weisel RD, Li R, Tumiati L, Coles JG. Effect of oxygen tension and cardiovascular operations on the myocardial antioxidant enzyme activities in patients with tetralogy of Fallot and aorta-coronary bypass. $\mathbf{J}$ Thorac Cardiovasc Surg 1992;104:159-64.

22. Del Nido PJ, Mickle DAG, Wilson G, Benson LN, Coles JG, Trusler GA. Evidence of myocardial free radical injury during elective repair of tetralogy of Fallot. Circulation 1987:76:174-9.

23. Allen BS, Rahman SK, Ilbawi M, Feinberg H, Bolling KS,
Kronon M. The detrimental effects of cardiopulmonary bypass in cyanotic infants: preventing the reoxygenation injury. Society of Thoracic Surgeons 1997; 33rd Annual Meeting: Abstract.

24. Rosenkranz ER, Okamoto F, Buckberg GD, Robertson JM, Vinten-Johansen J, Bugyi HI. Safety of prolonged aortic clamping with blood cardioplegia. III. Aspartate enrichment of glutamate-blood cardioplegia in energy-depleted hearts after ischemic and reperfusion injury. $\mathrm{J}$ Thorac Cardiovase Surg 1986;91:428-35.

25. Allen BS, Okamoto F, Buckberg GD, Bugyi HI, Young H. Leaf J, et al. Studies of controlled reperfusion after ischemia. $X V$. Immediate functional recovery after six hours of regional ischemia by careful control of conditions of reperfusion and composition of reperfusate. J Thorac Cardiovasc Surg 1986;92:621-35.

26. Boucek RJ Jr, Kasselberg AG, Boerth RC, Parrish MD, Graham TP Jr. Myocardial injury in infants with congenital heart disease: evaluation by creatine kinase MB isoenzyme analysis. Am J Cardiol 1982:50:129-35.

27. Graham TP Jr, Erath HG Jr, Buckspan GS, Fisher RD Myocardial anaerobic metabolism during isoprenaline infusion in a cyanotic animal model: possible cause of myocardial dysfunction in cyanotic congenital heart disease. Cardiovasc Res 1979;13:401-6.

28. Kirklin J, Barratt-Boyes B. Myocardial management during cardiac surgery with cardiopulmonary bypass. In: Kirklin JW, Barratt-Boyes BG, editors. Cardiac surgery. 2nd ed. New York: Churchill Livingstone; 1993. p. 129-66.

29. Aoki M, Nomura F, Kawata H, Mayer JE Jr. Effect of calcium and preischemic hypothermia on recovery of myocardial function after cardioplegic ischemia in neonatal lambs. J Thorac Cardiovasc Surg 1993:105:207-13.

\section{Discussion}

Dr. Davis C. Drinkwater (Los Angeles, Calif.). Using a neonatal piglet model, Dr. Bolling and his colleagues from University of Illinois have demonstrated the superiority of blood cardioplegia over crystalloid cardioplegia (St. Thomas' Hospital) in preinjured hypoxic pediatric hearts. An intermittent ischemic time of 70 minutes in uninjured hearts showed no such benefit. My comments and questions are limited to the abstract and the presentation because I have not had the benefit of previewing the manuscript. I am sure the article itself will further elucidate many of the issues that I am going to raise.

First let me commend you on your study, which further adds to the information concerning benefits of blood cardioplegia in pediatric hearts. Previous work by my colleagues and me, as well as others, both in intact and isolated piglet heart models, found that a hypoxic insult of an oxygen tension in the range of $25 \mathrm{~mm} \mathrm{Hg}$ was required to significantly acutely preinjure the neonatal heart, which is extremely adaptive under hypoxic conditions and in an acute model. These also required substrate repletion (glutamate and aspartate). How do you account, Dr. Bolling, for the fact that the rather moderate hypoxia that you used caused so profound an injury? Did you have an opportunity to measure any tissue levels of energy substrates, such as glucose or ATP? 
Dr. Bolling. Our model of acute hypoxia results in a "stress" injury, which is similar to the injury reported by Del Nido and colleagues after reoxygenation of cyanotic infants undergoing repair of tetralogy of Fallot. This injury may be less severe than other experimental models, but it does allow us to test cardioplegic solutions using stressed neonatal hearts subjected to oxygen saturations that are similar to those seen in hypoxic newborn infants. The fact that we saw differences between cardioplegic solutions in these less injured hearts may mean that the differences might have been even more pronounced had we used a more severe injury. Furthermore, we demonstrated in a previous series of experiments that our model of acute hypoxia does not result in ischemia. The reason is that piglets are given transfusions before acute hypoxia to simulate the chronic adaptive change of erythrocytosis, thereby increasing oxygen-carrying capacity. Evidence for the adequacy of cellular oxygen during hypoxia in these experiments was demonstrated by oxygen consumption data, lack of lactate production, and preservation of ATP levels. Therefore, unlike your hypoxic insult, our model of hypoxia does not result in significant substrate depletion. However, in cyanotic children ATP may be depleted as a result of exercise or stress, either before or during operative repair. Because ATP depletion is known to lead to postoperative myocardial depression and may subject the heart to a reperfusion injury as well as a reoxygenation injury, cyanotic infants may be even more dependent on the type of cardioplegic protection. We also measured postbypass ATP levels (see Table IV). These results demonstrate depression of ATP and the ATP/ADP ratio in hypoxic piglets protected with a crystalloid cardioplegic solution, suggesting that these hearts were not protected as well as hearts given blood cardioplegia.

Dr. Drinkwater. Second, I have some technical questions concerning the comparability of the protocols used in the solutions and the technique of myocardial preservation. Inasmuch as each heart was used as its own control; at what point (before or after hypoxia) were measurements taken, given recovery percentages greater than $100 \%$ of the control?

Dr. Bolling. Measurements were made before CPB or any hypoxic intervention and 1 hour after removal of the aortic crossclamp. The greatest recovery was $106 \%$ of control, which is not statistically different from the prebypass values.

Dr. Drinkwater. Was there any difference after hypoxia?

Dr. Bolling. Hypoxia resulted in an increase in heart rate from 130 to 150 beats $/ \mathrm{min}$ up to 190 to 220 beats $/ \mathrm{min}$, decreased systemic vascular resistance index, increased pulmonary vascular resistance index, and did not significantly affect cardiac output. All piglets tolerated 1 hour of hypoxia with stable hemodynamics.

Dr. Drinkwater. You mentioned that you administered the blood cardioplegic solution every 20 minutes and the crystalloid solution every 30 minutes. Why was the time period used for the the two groups not more comparable?

Dr. Bolling. As extensively discussed in the manuscript, we chose to deliver each cardioplegic solution as recommended by numerous experimental and clinical investigators, using those strategies that have been shown to optimize protection with each method. Although using identical cardioplegic protocols may be preferred scientifically, it does not allow one to test each solution to its maximal clinical potential. Furthermore, if we had followed the same protocol for both solutions, which protocol should we have chosen, one designed primarily for blood or one designed primarily for crystalloid cardioplegia? For instance, if we used a protocol developed for blood cardioplegia which included warm induction and warm reperfusion, we would correctly have been criticized for delivering crystalloid cardioplegia in a detrimental manner. However, avoiding the use of warm induction in both groups does not answer the question of which solution is better, because the two solutions are not used to their full advantage. Therefore blood cardioplegia was given every 20 minutes and crystalloid every 30 minutes, because these protocols have been recommended to achieve optimal protection with each method. Many investigators have also noted that multidose crystalloid cardioplegia may offer no advantage over a single dose, and may indeed be detrimental. To maximize crystalloid protection with less frequent infusions, we maintained hypothermia by lowering bypass temperature to $25^{\circ} \mathrm{C}$, room temperature to $18^{\circ} \mathrm{C}$, and using topical $4^{\circ} \mathrm{C}$ cooling. Although we considered administering the crystalloid cardioplegic solution more frequently, we were concerned that we would then be criticized by those investigators who have demonstrated that frequent multidose crystalloid cardioplegic infusions can be detrimental. Therefore we chose to deliver each solution as it is given in most experimental and clinical studies.

Dr. Drinkwater. What about the use of topical cooling? Your abstract states that you packed the heart in ice. Is that actually clinically relevant given our concerns for phrenic nerve injuries and other problems?

Dr. Bolling. We apologize for this inaccuracy in our original abstract. The heart was not packed in ice. Instead, $4^{\circ} \mathrm{C}$ cold saline slush was applied to all hearts. This has not been shown to cause phrenic nerve injury in infants, and it is extensively used, especially by surgeons using crystalloid cardioplegia. In addition, if this had caused myocardial injury, we would have expected it to affect both blood and crystalloid groups equally. However, functional recovery was complete in hypoxic hearts protected with blood cardioplegia, whereas hearts protected with crystalloid cardioplegia showed marked depression.

Dr. Drinkwater. Did you control for calcium levels, particularly during reperfusion?

Dr. Bolling. Yes, we did. In the crystalloid groups a hypocalcemic bypass prime was used both for cooling and for reperfusion. Although a normocalcemic bypass prime was used in the blood cardioplegia groups, the cardioplegic solution was made hypocalcemic by the addition of citrate, as depicted in Tables I and II.

Dr. Drinkwater. Third, vascular reactivity as a measurement of coronary vascular resistance has been interpreted in your study as endothelial cell function. Although this is quite possible, can you really conclude this in the absence of provocative endothelium-dependent and -independent stimulation and the absence of say, nitric oxide measurements, especially given the variability of the viscosity of your solutions? 
Dr. Bolling. We agree that we cannot identify the site of the vascular dysfunction on the basis of our results. Although we believe it is most likely due to a vascular endothelial cell injury, this cannot be proved with our data.

Dr. Drinkwater. Let me conclude by noting that prior studies in our laboratory over 10 years ago showed in an isolated piglet model that intermittent ischemia of 120 minutes had better recovery with blood cardioplegia over St. Thomas solution, and particularly if we added glutamate to the blood cardioplegic solution. In your model, 70 minutes may be adequate for most procedures, but may not reflect the more complex procedures such as LV outflow tract reconstruction. In very experienced hands, the left-sided aspect of the pulmonary autograft procedures routinely requires over 100 minutes of crossclamp time. Therefore it is possible that had you used a greater ischemic time, particularly in normal hearts, there might have been differences in recovery between these two solutions. Would you comment on this and, most important, on whether your group has adopted a selective approach to the noncyanotic patients in terms of cardioplegic management?

Dr. Bolling. We agree that 70 minutes may not be adequate to perform all complex neonatal myocardial repairs. In addition, because the neonatal myocardium may be more tolerant to ischemia than the adult myocardium, we believe that differences would probably have been seen had the crossclamp time been extended, especially since the ATP/ADP ratio was significantly reduced even in "normal" (nonhypoxic) hearts protected with crystalloid cardioplegia. Furthermore, in clinical practice congenital lesions usually result in either hypoxia or pressure-volume overload, and therefore "normal" hearts are probably uncommon, especially in the neonatal population. Because of these concerns, our group has not adapted a selective approach, and we use blood cardioplegia exclusively.

Dr. Pat O. Daily (San Diego, Calif.). Why did you use topical cooling in the pericardium with crystalloid cardioplegia and no myocardial surface cooling in the blood cardioplegia group?

Dr. Bolling. We apologize for the confusion on this issue. Although our original abstract mentions topical cooling only in the crystalloid cardioplegia group, we applied topical cooling to all hearts to try to make the groups as similar as possible.

Dr. Daily. My concern is that you mention ice slush as opposed to just cold saline solution. Could the addition of this ice have caused some of the injury to these hearts?

Dr. Bolling. Although the topical cooling was primarily cold saline solution, it did contain some particles of ice, making it somewhat of a slush solution. However, when we measured the temperature of the solution it was almost always approximately $4^{\circ} \mathrm{C}$, which has not been shown to be detrimental. In addition, had the ice particles been responsible for causing damage, we would have expected both groups to be affected equally. In contrast, only hypoxic hearts protected with a crystalloid cardioplegic solution showed any decrease in ventricular function. Therefore we do not believe the small quantity of ice in the topical saline solution was the reason for these results.

Dr. Gregory Misbach (San Bernardino, Calif.). I have one related question. Inasmuch as I used 20-minute intervals for either crystalloid or blood cardioplegia over the years, I would be suspicious that a 30 -minute interval might introduce another variable when trying to investigate the differences between crystalloid and blood cardioplegia. Are you able to deal with this issue?

Dr. Bolling. As mentioned in our discussion of Dr. Drinkwater's question and the manuscript, we chose these time intervals on the basis of the experience of numerous investigators. Blood cardioplegia was given every $20 \mathrm{~min}-$ utes, as is widely accepted. Conversely, numerous investigators have demonstrated that multidose crystalloid cardioplegia may not be beneficial, and can be potentially detrimental when given too frequently. Therefore we chose the 30-minute interval, as advocated by most clinical and experimental investigators. We were concerned that had we given crystalloid cardioplegia every 20 minutes, we would have instead been criticized for possibly injuring the hearts as a result of frequent administrations.

Dr. Misbach. By showing a change in vascular reactivity between the two groups, are you speculating that this might be a contributing mechanism to poor myocardial protection; that perhaps there was more even distribution of delivery of the cardioplegic solution because of the different vascular reactivity in the blood cardioplegia group?

Dr. Bolling. We believe that this increase in CVR during the infusion of crystalloid cardioplegia in hypoxic hearts probably represents an injury to vascular function. This increased CVR in the crystalloid group may result in less homogeneous cardioplegic distribution during the period of ischemia and, therefore, may compromise myocardial protection. 